\title{
MODEL JARINGAN SYARAF TIRUAN MEMPREDIKSI EKSPOR BATU BARA MENURUT NEGARA TUJUAN UTAMA DALAM MENDORONG LAJU PERTUMBUHAN EKONOMI
}

\author{
Rafiqa Dewi' ${ }^{1}$, Sundari Retno Andani ${ }^{2} \&$ Solikhun $^{3}$ \\ 1,2,3 AMIK Tunas Bangsa Pematangsiantar \\ Jl. Jend. Sudirman Blok A No. 1,2 \& 3 Pematangsiantar \\ E-mail: solikhun@amiktunasbangsa.ac.id
}

\begin{abstract}
Prediction is a process for estimating how many needs in the future. This study aims to predict the amount of coal exports according to the country the main goal in driving the pace of economic growth. The role of the agricultural sector in the national economy is very important and strategic. Coal is one of the fossil fuels. The general definition is a sedimentary rock that can burn, formed from organic deposits, mainly the remains of plants and formed through the process of pembatubaraan. The main elements consist of carbon, hydrogen and oxygen. Domestic production makes the government continue to implement coal export policies according to the state's main goal in driving the pace of economic growth in Indonesia. By using Artificial Neural Networks and backpropagation algorithms, architectural models will be sought to predict the amount of coal exports according to the state's main goal in driving the pace of economic growth to determine steps to assist the government in exporting coal based on the main destination country. This study uses 12 input variables with 1 target. Using 4 architectural models to test the data to be used for prediction, namely models 12-8-1, 12-16-1, 12-32-1 and 12-64-1. The best architectural model results obtained are 12-16-1 architectural models with 100\% truth accuracy, the number of epoch 2602 and MSE is 0.0032. By using this model, predictions of coal exports are in accordance with the main destination countries with 100\% accuracy.
\end{abstract}

Keywords: Coal, Exports, predictions, backpropagation, Artificial Neural Networks

\section{Abstrak}

Prediksi adalah proses untuk memperkirakan berapa banyak kebutuhan di masa depan. Studi ini bertujuan untuk memprediksi jumlah ekspor batubara menurut negara tujuan utama dalam mendorong laju pertumbuhan ekonomi. Peran sektor pertanian dalam ekonomi nasional sangat penting dan strategis. Batubara adalah salah satu bahan bakar fosil. Definisi umum adalah batuan sedimen yang dapat terbakar, terbentuk dari endapan organik, terutama sisa-sisa tanaman dan terbentuk melalui proses pembatubaraan. Unsur utama terdiri dari karbon, hidrogen, dan oksigen. Produksi dalam negeri membuat pemerintah terus menerapkan kebijakan ekspor batubara sesuai dengan tujuan utama negara dalam mendorong laju pertumbuhan ekonomi di Indonesia. Dengan menggunakan Jaringan Saraf Tiruan dan algoritma backpropagation, model arsitektur akan dicari untuk memprediksi jumlah ekspor batubara sesuai dengan tujuan utama negara dalam mendorong laju pertumbuhan ekonomi untuk menentukan langkah-langkah untuk 
membantu pemerintah dalam mengekspor batubara berdasarkan negara tujuan utama . Penelitian ini menggunakan 12 variabel input dengan 1 target. Menggunakan 4 model arsitektur untuk menguji data yang akan digunakan untuk prediksi, yaitu model 12-8-1, 12 16-1, 12-32-1 dan 12-64-1. Hasil model arsitektur terbaik yang diperoleh adalah model arsitektur 12-16-1 dengan akurasi 100\%, jumlah zaman 2602 dan MSE adalah 0,0032. Dengan menggunakan model ini, prediksi ekspor batubara sesuai dengan negara tujuan utama dengan akurasi $100 \%$.

Kata kunci: Batubara, Ekspor, prediksi, backpropagation, Jaringan Syaraf Tiruan

\section{PENDAHULUAN}

Batu bara adalah salah satu bahan bakar fosil. Pengertian umumnya adalah batuan sedimen yang dapat terbakar, terbentuk dari endapan organik, utamanya adalah sisa-sisa tumbuhan dan terbentuk melalui proses pembatubaraan yang terjadi pada negara tujuan utama. Unsur-unsur utamanya terdiri dari karbon, hidrogen dan oksigen. Batu bara juga adalah batuan organik yang memiliki sifat-sifat fisika dan kimia yang kompleks yang dapat ditemui dalam berbagai bentuk. Analisis unsur memberikan rumus formula empiris seperti $\mathrm{C}_{137} \mathrm{H}_{97} \mathrm{O}_{9} \mathrm{NS}$ untuk bituminus dan $\mathrm{C}_{240} \mathrm{H}_{90} \mathrm{O}_{4} \mathrm{NS}$ untuk antrasit. (Wikipedia).

Perdagangan bebas di era globalisasi saat ini banyak melibatkan perdagangan antarnegara. Hal ini terjadi karena adanya kebutuhan akan suatu produk yang tidak dapat dihasilkan oleh suatu negara. Seiring dengan perkembangan industrialisasi modern saat ini, kebutuhan akan energi dunia menjadi semakin besar agar roda industri dapat terus berjalan. Batubara merupakan salah satu dari berbagai bahan bakar fosil untuk menggerakkan mesin industri. Batubara digunakan diberbagai sektor, termasuk produksi besi dan baja, pembangkit listrik dan pabrik semen. Oleh sebab itu negara-negara di dunia berusaha untuk memenuhi pasokan energi dalam negerinya agar industrinya dapat terus berjalan. Industri batubara adalah suatu industri dimana batubara ditambang secara komersial lebih di 50 negara dan digunakan di lebih dari 70 negara. Konsumsi batubara di Asia sekitar 65,6\% dari konsumsi batubara dunia. Tingginya permintaan batubara di kawasan ini, memberikan prospek pasar yang menarik bagi para eksportir batubara Indonesia. Indonesia merupakan salah satu eksportir batubara yang memiliki peran penting sebagai pemasok batubara di pasar internasional yaitu sekitar 24\%. Jepang, Cina, Korea Selatan, dan Taiwan adalah negara-negara tujuan ekspor utama batubara Indonesia.

Dalam rangka mendorong laju pertumbuhan ekonomi menjadi lebih tinggi, Pemerintah sangat membutuhkan dukungan dari seluruh sektor atau bidang yang dapat menambah income atau pendapatan pemerintah. Jika pengeluaran lebih besar dari pendapatan maka pemerintah akan mengalami defisit dan sulit dalam menjalankan roda kepemerintahan dengan baik. Salah satu pendapat yang penting adalah dari sektor perdagangan yaitu ekspor dan impor. Negara Indonesia merupakan negara pengekspor Batu Bara. Pemerintah harus bisa melakukan prediksi Batu Bara kedepan agar pihak pemerintah dapat mengambil langkah atau kebijakan bagaimana membuat strategi-strategi yang handal dalam upaya meningkatkan jumlah ekspor Batu Bara ke depan. Begitu juga bagi masyarakat 
sebagai penghasil Batu Bara, mereka harus bisa memperbaiki kualitas dan kuantitas hasil penambangan Batu Bara. Prediksi ekspor Batu Bara ke depan ditentukan berdasarkan data ekspor Batu Bara sebelumnya dimulai dari tahun 2002 sampai tahun 2015.

Jaringan syaraf tiruan (JST) adalah paradigm pemrosesan suatu informasi yang terinspirasi oleh sistem sel syaraf biologi. Jaringan ini biasanya diimplementasikan dengan menggunakan komponen elektronik atau disimulasikan pada aplikasi computer [1]. Metode ini termasuk kedalam rumpun kecerdasan buata. Kecerdasan buatan atau disebut juga Artificial Intelegent (AI) merupakan salah satu bagian dari ilmu komputer yang mempelajari bagaimana membuat mesin (komputer) dapat melakukan pekerjaan seperti dan sebaik yang dilakukan oleh manusia bahkan bisa lebih baik daripada yang dilakukan manusia. Algoitma yang digunakan pada penelitian ini adalah Backpropagation yaitu sebuah metode sistematika untuk pelatihan multilayer Jaringan Syaraf Tiruan. Jaringan Backpropagation merupakan salah satu algoritma yang sering digunakan dalam menyelesaikan masalah-masalah yang rumit (Anwar, 2011). Algoritma ini juga dipakai pada aplikasi pengaturan karena proses pelatihannya didasarkan pada hubungan yang sederhana [2].

Penelitian ini akan memberikan sebuah model arsitektur untuk memprediksi jumlah ekspor batu bara menurut negara tujuan utama dalam mendorong laju pertumbuhan ekonomi, dimana nantinya hasil penelitian ini dapat dijadikan sebuah referensi untuk pemerintah dalam menentukan kebijakankebijakan dikedepannya. Penelitian ini diharapkan akan memberikan data yang akurat dan realistis sehingga layak untuk menjadi sebuah tolak ukur atau gambaran ekspor batu bara menurut negara tujuan utama dalam mendorong laju pertumbuhan ekonomi.

\section{METODOLOGI PENELITIAN}

\subsection{Kecerdasan Buatan (Artificial Intelegent)}

Kecerdasan buatan atau disebut juga Artificial Intelligence (AI) merupakan salah satu bagian dari ilmu komputer yang mempelajari bagaimana membuat mesin (komputer) dapat melakukan pekerjaan seperti dan sebaik yang dilakukan oleh manusia bahkan bisa lebih baik daripada yang dilakukan manusia. Menurut John McCarthy dalam Dahria (2008), Artificial Intelligence (AI) adalah untuk mengetahui dan memodelkan proses-proses berpikir manusia dan mendesain mesin agar dapat menirukan perilaku manusia. Cerdas, berarti memiliki pengetahuan dan pengalaman, penalaran, bagaimana membuat keputusan dan mengambil tindakan moral yang baik[3].

\subsection{Jaringan Saraf Tiruan}

Jaringan Saraf Tiruan (JST) merupakan salah satu representasi buatan otak manusia yang selalu mencoba untuk mensimulasikan proses pembelajaran pada otak manusia[4]. 


\subsection{Arsitektur Backpropogation}

Backpropagation terdiri dari n buah masukan (ditambah sebuah bias), sebuah layar tersembunyi yang terdiri dari $\mathrm{p}$ unit (ditambah sebuah bias), serta m buah unit keluaran. Voj dan Wok masing-masing adalah bias untuk unit tersembunyi kej dan untuk output ke-k. Bias Voj dan Wok berperilaku seperti bobot dimana output bias ini selalu sama dengan $1[2]$.

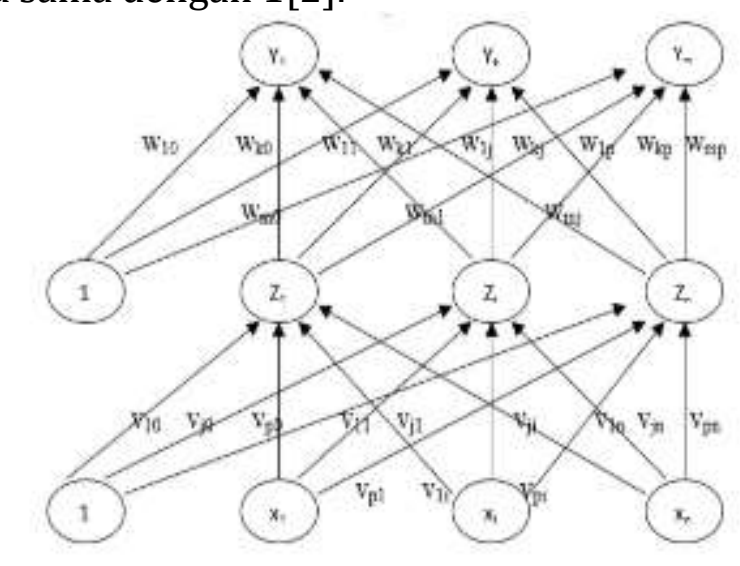

Gambar 1 Arsitektur Backpropogation

\subsection{Langkah-Langkah Jaringan Saraf Tiruan Backpropagation}

Langkah-langkah dalam Jaringan Saraf Tiruan Backpropagation meliputi tiga fase yaitu :

\section{a. Fase I : Propagasi Maju}

Selama propagasi maju, sinyal masukan $(=x i)$ dipropagasikan ke lapis tersembunyi menggunakan fungsi aktivasi yang ditentukan. Keluaran dari setiap unit lapis tersembunyi $(=z j)$ tersebut selanjutnya dipropagasikan maju lagi ke lapis tersembunyi di atasnya menggunakan fungsi aktivasi yang ditentukan. Demikian seterusnya hingga menghasilkan keluaran jaringan $(=$ $y k)$. Berikutnya, keluaran jaringan $(=y k)$ dibandingkan dengan target yang harus dicapai $(=t k)$. Selisih $t k-y k$ adalah kesalahan yang terjadi. Jika kesalahan ini lebih kecil dari batas toleransi yang ditentukan, maka iterasi dihentikan. Akan tetapi apabila kesalahan masih lebih besar dari batas toleransinya, maka bobot setiap garis dalam jaringan akan dimodifikasikan untuk mengurangi kesalahan yang terjadi.

b. Fase II : Propagasi Mundur

Berdasarkan kesalahan $t k-y k$, dihitung faktor $\delta k(k=1,2, \ldots, m)$ yang dipakai untuk mendistribusikan kesalahan di unit $y k$ ke semua unit tersembunyi yang terhubung langsung dengan $y k$. $\delta k$ juga dipakai untuk mengubah bobot garis yang menghubungkan langsung dengan unit keluaran. Dengan cara yang sama, dihitung $\delta j$ di setiap unit di lapis tersembunyi sebagai dasar perubahan bobot semua garis yang berasal dari unit tersembunyi di lapis di bawahnya. Demikian seterusnya hingga faktor $\delta$ di unit tersembunyi yang berhubungan langsung dengan unit masukan dihitung.

c. Fase III : Perubahan Bobot

Setelah semua faktor $\delta$ dihitung bobot semua garis dimodifikasi bersamaan. 
Perubahan bobot suatu garis didasarkan atas faktor $\delta$ neuron di lapis atasnya. Sebagai contoh, perubahan bobot garis yang menuju ke lapis keluaran didasarkan atas dasar $\delta \mathrm{k}$ yang ada di unit keluaran.

Ketiga fase tersebut diulang-ulang terus hingga kondisi penghentian dipenuhi. Umumnya kondisi penghentian yang sering dipakai adalah jumlah iterasi atau kesalahan. Iterasi akan dihentikan jika jumlah iterasi yang dilakukan sudah melebihi jumlah maksimum iterasi yang ditetapkan, atau jika kesalahan yang terjadi sudah lebih kecil dari batas toleransi yang diijinkan[5].

Algoritma Pelatihan backpropagation dengan satu layar tersembunyi (dengan fungsi aktivasi sigmoid biner) adalah[6]:

Langkah 0 : Inisialisasi semua bobot dengan bilangan acak kecil.

Langkah 1 : Jika kondisi penghentian belum dipenuhi, lakukan langkah 2-8.

Langkah 2 : Untuk setiap pasang data pelatihan, lakukan langkah 3-8.

Langkah 3 : Langkah 3 (langkah 3-5 merupakan fase 1).

Tiap unit masukan menerima sinyal dan meneruskannya ke unit tersembunyi diatasnya.

Langkah 4 : Hitung semua keluaran di unit tersembunyi zj $(j=1,2, \ldots, p)$.

$$
\begin{gathered}
Z_{-} \text {net }_{j}=V_{j \circ}+\sum_{i=1}^{n} X_{i} V_{j i} \\
Z_{j}=f\left(Z_{-} \text {net }_{j}\right)=\frac{1}{1+\exp ^{\left(-z_{-} \text {net }_{j}\right)}}
\end{gathered}
$$

Langkah 5 : Hitung semua keluaran jaringan di unit keluaran $y k(k=1,2, \ldots, m)$ :

$$
y_{\text {net }}=W_{k o}+\sum_{j=1}^{p} Z_{j} W_{k j}
$$

Menghitung kembali sesuai dengan fungsi aktivasi:

$$
\begin{aligned}
y_{k} & =f\left(y_{1} n t_{k j}\right. \\
Z_{j} & \left.=\frac{1}{1+\operatorname{Exp}\left(-y, n s t_{k}\right)}\right)
\end{aligned}
$$

Langkah 6 : (langkah 6-7 merupakan fase 2)

Hitung faktor $\delta$ unit keluaran berdasarkan kesalahan di setiap unit keluaran $y k(k=1,2, \ldots, m)$.

$$
\begin{gathered}
\delta_{k}=\left(t_{k}-y_{k}\right) f^{\prime}\left(y_{-} \text {net } t_{k}\right)=\left(t_{k}-y_{k}\right) y_{k}\left(1-y_{k}\right) \\
t_{k}=\text { target }
\end{gathered}
$$

keluaran $\delta k$ merupakan unit kesalahan yang akan dipakai dalam perubahan bobot layar dibawahnya. Hitung perubahan bobot wkj dengan laju pemahaman $\alpha$.

$$
\Delta W_{k j}=\alpha \delta_{k} z_{j j}, k=1,2, \ldots, m, j=0,1, \ldots, p
$$

Langkah 7 : Hitung faktor $\delta$ unit tersembunyi berdasarkan kesalahan di setiap unit tersembunyi $z j(j=1,2, \ldots, p)$

$$
\delta_{\text {net }_{j}}=\sum_{k=1}^{m} \delta_{k} W_{k j}
$$


Faktor $\delta$ unit tersembunyi.

$$
\delta_{j}=\delta_{\text {net }_{j}} f^{\prime}\left(Z_{-} \text {net }_{j}\right)=\delta_{\text {net }_{j}} z_{j}\left(1-z_{j}\right)
$$

Hitung suku perubahan bobot vji.

$$
\Delta V_{j i}=\alpha \delta_{j} x_{i}, j=1,2, \ldots, p, i=0,1, \ldots, n
$$

Langkah 8 : Hitung semua perubahan bobot. Perubahan bobot garis yang menuju ke unit keluaran, yaitu

$$
\begin{gathered}
W_{k j}(\text { baru })=W_{k j}(\text { lama })+\Delta W_{k j}, \\
k=1,2, \ldots, m, j=0,1, \ldots, p n
\end{gathered}
$$

Perubahan bobot garis yang menuju ke unit tersembunyi, yaitu:

$$
\begin{gathered}
V_{j i}(\text { baru })=V_{j i}(\text { lama })+\Delta V_{j i}, \\
j=1,2, \ldots, p, i=0,1, \ldots, n
\end{gathered}
$$

\subsection{Karakteristik Jaringan Saraf Tiruan}

Jaringan Saraf Tiruan memiliki beberapa karakteristik yang unik, diantaranya adalah :

1. Kemampuan untuk belajar

2. Kemampuan untuk belajar

3. Kemampuan untuk menyolusikan permasalahan yang tidak bisa atau kurang baik bila dimodelkan sebagai sistem linier, yang menjadi persyaratan pada beberapa metode peramalan lainnya, seperti model data deret waktu (time series model)[7].

\section{HASIL DAN PEMBAHASAN}

\subsection{Perancangan Sistem}

\subsubsection{Pendefinisian Input dan Target}

Data Ekspor Batu Bara Menurut Negara Tujuan Utama akan diolah oleh Jaringan Saraf Tiruan dengan metode backpropogation. Agar data dapat dikenali oleh Jaringan Saraf Tiruan, maka data harus direpresentasikan ke dalam bentuk numerik antara 0 sampai dengan 1 , baik variabel maupun isinya yang merupakan masukan data Data Ekspor Batu Bara Menurut Negara Tujuan Utama sebagai pengenalan pola dan keluaran yang merupakan prediksi Data Ekspor Batu Bara Menurut Negara Tujuan Utama yang diperoleh dari model arsitektur terbaik pada saat penentuan pola terbaik. Hal ini dikarenakan jaringan menggunakan fungsi aktivasi sigmoid biner (logsig) yang rangenya dari 0 sampai 1 . Nilai-nilai yang digunakan diperoleh berdasarkan kategori dari masing-masing variabel selain juga untuk memudahkan mengingat dalam pendefinisiannya.

\subsubsection{Pendefinisian Input}

Variabel Data Ekspor Batu Bara Menurut Negara Tujuan Utama adalah kriteria yang menjadi acuan dalam pengambilan keputusan pada penilaian dengan menggunakan Jaringan Saraf Tiruan. Variabel ditentukan dengan cara melihat ketergantungan data terhadap penelitian yang dilakukan. Kriteria yang digunakan berdasarkan Data Badan Pusat Statistik Nasional dari website url: www.bps.go.id. 
Adapun daftar variabel dalam memprediksi Data Ekspor Batu Bara Menurut Negara Tujuan Utama tabel 1 :

Tabel 1: Daftar Kriteria Pelatihan dan Pengujian

\section{Pelatihan}

\section{Pengujian}

\begin{tabular}{lcclcc} 
No & Variabel & Nama Kriteria & No & Variabel & Nama Kriteria \\
\hline $\mathbf{1}$ & X1 & Data Tahun 2002 & $\mathbf{1}$ & X1 & Data Tahun 2003 \\
$\mathbf{2}$ & X2 & Data Tahun 2003 & $\mathbf{2}$ & X2 & Data Tahun 2004 \\
$\mathbf{3}$ & X3 & Data Tahun 2004 & $\mathbf{3}$ & X3 & Data Tahun 2005 \\
$\mathbf{4}$ & X4 & Data Tahun 2005 & $\mathbf{4}$ & X4 & Data Tahun 2006 \\
$\mathbf{5}$ & X5 & Data Tahun 2006 & $\mathbf{5}$ & X5 & Data Tahun 2007 \\
$\mathbf{6}$ & X6 & Data Tahun 2007 & $\mathbf{6}$ & X6 & Data Tahun 2008 \\
$\mathbf{7}$ & X7 & Data Tahun 2008 & $\mathbf{7}$ & X7 & Data Tahun 2009 \\
$\mathbf{8}$ & X8 & Data Tahun 2009 & $\mathbf{8}$ & X8 & Data Tahun 2010 \\
$\mathbf{9}$ & X9 & Data Tahun 2010 & $\mathbf{9}$ & X9 & Data Tahun 2011 \\
$\mathbf{1 0}$ & X10 & Data Tahun 2011 & $\mathbf{1 0}$ & X10 & Data Tahun 2012 \\
$\mathbf{1 1}$ & X11 & Data Tahun 2012 & $\mathbf{1 1}$ & X11 & Data Tahun 2013 \\
$\mathbf{1 2}$ & X12 & Data Tahun 2013 & $\mathbf{1 2}$ & X12 & Data Tahun 2014 \\
$\mathbf{1 3}$ & Target & Data Tahun 2014 & $\mathbf{1 3}$ & Target & Data Tahun 2015 \\
\hline \multicolumn{5}{c}{ Sumber : Badan Pusat Statistik Nasional }
\end{tabular}

Data input diperoleh dari website Badan Pusat Statistik Nasional tentang Ekspor Batu Bara Menurut Negara Tujuan Utama. Data sampel yang digunakan adalah Ekspor Batu Bara Menurut Negara Tujuan Utama Tahun 2002 Tahun 2015 yang terdiri dari 22 yang lengkap data dan masing masing data memiliki 12 variabel dan 1 target. Data ini nantinya akan ditransformasikan ke sebuah data antara 0 sampai 1 sebelum dilakukan pelatihan dan pengujian menggunakan Jaringan Saraf Tiruan metode backpropagation dengan rumus :

$$
x^{\prime}=\frac{0.8(x-a)}{b-a}+0.1
$$

\subsubsection{Pendefinisian Target}

Adapun data target pelatihan Data Ekspor Batu Bara Menurut Negara Tujuan Utama Tahun 2014, Sedangkan data target Pengujian Data Ekspor Batu Bara Menurut Negara Tujuan Utama Tahun 2015.

\subsection{Pengolahan Data}

Pengolahan data dilakukan dengan bantuan Matlab r2011a aplikasi perangkat lunak. Sampel Data adalah Ekspor Batu Bara Menurut Negara Tujuan Utama. Data ini akan digunakan pada data pelatihan dan data pengujian. Sampel data yang telah diproses dan ditranformasikan adalah sebagai berikut. 
Kumpulan jurnaL Ilmu Komputer (KLIK)

Volume 06, No.02 Juni 2019

ISSN: $2406-7857$

\begin{tabular}{|c|c|c|c|c|c|c|c|c|c|c|c|c|c|c|}
\hline \multirow[b]{2}{*}{$\begin{array}{l}\text { Negara } \\
\text { Tujuan }\end{array}$} & \multicolumn{14}{|c|}{ Tabel 2. Sampel Data Mentah Ekspor Batu Bara Menurut Negara Tujuan Utama } \\
\hline & 2002 & 2003 & 2004 & 2005 & 2006 & 2007 & 2008 & 2009 & 2010 & 2011 & 2012 & 2013 & 2014 & 2015 \\
\hline Jepang & 16705.9 & 19919.4 & 22612.1 & 27312.8 & 35295.7 & 35198.5 & 36259.8 & 32217.7 & 35266.7 & 35364.0 & 35518.3 & 37711.5 & 35584.6 & 32509.0 \\
\hline Hongkong & 4098.5 & 6799.6 & 7367.3 & 9408.6 & 10985.2 & 11235.5 & 10497.1 & 10714.2 & 9706.2 & 11868.2 & 11984.8 & 12964.3 & 12581.6 & 9833.2 \\
\hline $\begin{array}{l}\text { Korea } \\
\text { Selatan }\end{array}$ & 7461.7 & 7856.9 & 11669.3 & 14376.6 & 21314.1 & 27371.5 & 26286.8 & 33418.4 & 43275.6 & 39598.2 & 37899.1 & 36273.3 & 35631.5 & 34015.7 \\
\hline Taiwan & 12780.3 & 15607.8 & 17765.5 & 17895.8 & 26723.8 & 24863.1 & 24669.4 & 24723.4 & 25002.2 & 27131.8 & 29105.2 & 28323.3 & 27271.8 & 24393.4 \\
\hline Cina & 2531.4 & 534.0 & 1473.1 & 2503.2 & 6656.5 & 14122.3 & 15673.7 & 39330.8 & 74805.0 & 104143.4 & 115702.1 & 130393.4 & 99280.3 & 72740.8 \\
\hline Thailand & 3822.1 & 4266.3 & 4787.2 & 6404.5 & 8475.1 & 11963.2 & 12822.8 & 11229.7 & 13081.8 & 13293.9 & 14676.0 & 14365.0 & 16241.5 & 17865.1 \\
\hline Pilipina & 3131.6 & 3082.9 & 3603.1 & 3906.1 & 5818.2 & 6023.5 & 6338.0 & 7518.1 & 11110.9 & 10989.7 & 11636.2 & 14508.8 & 15021.3 & 15823.2 \\
\hline Malaysia & 3285.4 & 5174.2 & 6112.8 & 7399.8 & 8782.6 & 9376.5 & 11104.3 & 12483.3 & 15535.7 & 17337.5 & 16138.0 & 17128.9 & 14494.0 & 16567.5 \\
\hline India & 5059.5 & 7812.7 & 10674.1 & 16255.4 & 20742.4 & 25179.1 & 26327.5 & 39108.9 & 51254.3 & 74723.2 & 96076.0 & 118288.5 & 136352.1 & 124481.5 \\
\hline $\begin{array}{l}\text { Amerika } \\
\text { Serikat }\end{array}$ & 1074.6 & 1913.6 & 1959.9 & 2050.3 & 3740.8 & 4557.7 & 3993.8 & 2081.6 & 1936.5 & 805.4 & 215.6 & 1177.4 & 1311.8 & 731.7 \\
\hline Italia & 2786.5 & 4536.4 & 5198.1 & 6285.5 & 7637.8 & 6193.8 & 5592.8 & 5797.0 & 6306.3 & 5080.8 & 4082.8 & 3016.6 & 3516.3 & 3106.0 \\
\hline Spanyol & 2720.1 & 2938.3 & 2775.7 & 3317.0 & 4444.9 & 4308.6 & 4387.4 & 4808.4 & 1564.3 & 3559.3 & 5704.8 & 4078.0 & 4071.5 & 4826.5 \\
\hline Lainnya & 5881.4 & 6698.5 & 8526.0 & 9789.8 & 17701.0 & 14125.7 & 13327.6 & 7976.8 & 7279.8 & 6654.3 & 5414.0 & 5924.0 & 6880.1 & 9994.3 \\
\hline
\end{tabular}

\section{Sumber : Badan Pusat Statistik Nasional}

Tabel 3. Sampel dari data yang telah ditransformasikan

\begin{tabular}{cccccccccccccc}
\hline $\mathbf{X 1}$ & $\mathbf{X 2}$ & $\mathbf{X 3}$ & $\mathbf{X 4}$ & $\mathbf{X 5}$ & $\mathbf{X 6}$ & $\mathbf{X 7}$ & $\mathbf{X 8}$ & $\mathbf{X 9}$ & $\mathbf{X 1 0}$ & $\mathbf{X 1 1}$ & $\mathbf{X 1 2}$ & $\mathbf{X 1 3}$ & TARGET \\
\hline $\mathbf{0 . 1 9 6 9}$ & 0.2158 & 0.2316 & 0.2592 & 0.3061 & 0.3056 & 0.3118 & 0.2881 & 0.3060 & 0.3065 & 0.3075 & 0.3203 & 0.3078 & 0.2898 \\
$\mathbf{0 . 1 2 2 8}$ & 0.1387 & 0.1420 & 0.1540 & 0.1633 & 0.1648 & 0.1604 & 0.1617 & 0.1558 & 0.1685 & 0.1692 & 0.1749 & 0.1727 & 0.1565 \\
$\mathbf{0 . 1 4 2 6}$ & 0.1449 & 0.1673 & 0.1832 & 0.2240 & 0.2596 & 0.2532 & 0.2951 & 0.3530 & 0.3314 & 0.3214 & 0.3119 & 0.3081 & 0.2986 \\
$\mathbf{0 . 1 7 3 8}$ & 0.1905 & 0.2031 & 0.2039 & 0.2558 & 0.2448 & 0.2437 & 0.2440 & 0.2457 & 0.2582 & 0.2698 & 0.2652 & 0.2590 & 0.2421 \\
$\mathbf{0 . 1 1 3 6}$ & 0.1019 & 0.1074 & 0.1134 & 0.1378 & 0.1817 & 0.1908 & 0.3299 & 0.5383 & 0.7107 & 0.7787 & 0.8650 & 0.6821 & 0.5262 \\
$\mathbf{0 . 1 2 1 2}$ & 0.1238 & 0.1269 & 0.1364 & 0.1485 & 0.1690 & 0.1741 & 0.1647 & 0.1756 & 0.1769 & 0.1850 & 0.1831 & 0.1942 & 0.2037 \\
$\mathbf{0 . 1 1 7 1}$ & 0.1168 & 0.1199 & 0.1217 & 0.1329 & 0.1341 & 0.1360 & 0.1429 & 0.1640 & 0.1633 & 0.1671 & 0.1840 & 0.1870 & 0.1917 \\
$\mathbf{0 . 1 1 8 0}$ & 0.1291 & 0.1347 & 0.1422 & 0.1503 & 0.1538 & 0.1640 & 0.1721 & 0.1900 & 0.2006 & 0.1936 & 0.1994 & 0.1839 & 0.1961 \\
$\mathbf{0 . 1 2 8 5}$ & 0.1446 & 0.1615 & 0.1943 & 0.2206 & 0.2467 & 0.2534 & 0.3286 & 0.3999 & 0.5378 & 0.6633 & 0.7939 & 0.9000 & 0.8302 \\
$\mathbf{0 . 1 0 5 0}$ & 0.1100 & 0.1103 & 0.1108 & 0.1207 & 0.1255 & 0.1222 & 0.1110 & 0.1101 & 0.1035 & 0.1000 & 0.1057 & 0.1064 & 0.1030 \\
$\mathbf{0 . 1 1 5 1}$ & 0.1254 & 0.1293 & 0.1357 & 0.1436 & 0.1351 & 0.1316 & 0.1328 & 0.1358 & 0.1286 & 0.1227 & 0.1165 & 0.1194 & 0.1170 \\
$\mathbf{0 . 1 1 4 7}$ & 0.1160 & 0.1150 & 0.1182 & 0.1249 & 0.1241 & 0.1245 & 0.1270 & 0.1079 & 0.1196 & 0.1323 & 0.1227 & 0.1227 & 0.1271 \\
$\mathbf{0 . 1 3 3 3}$ & 0.1381 & 0.1488 & 0.1563 & 0.2028 & 0.1817 & 0.1771 & 0.1456 & 0.1415 & 0.1378 & 0.1305 & 0.1335 & 0.1392 & 0.1575 \\
\hline
\end{tabular}

\subsection{Perancangan Arsitektur Jaringan Saraf Tiruan}

Sumber : Badan Pusat Statistik Nasional

Jaringan yang digunakan untuk dalam memprediksi Ekspor Batu Bara Menurut Negara Tujuan Utama dengan backpropogation dengan langkah pembelajaran feedforward. Jaringan ini memiliki beberapa lapisan, yaitu lapisan masukan (input), lapisan keluaran (output) dan beberapa lapisan tersembunyi (hidden). Lapisan tersembunyi tersebut membantu jaringan untuk dapat mengenali lebih banyak pola masukan dibandingkan dengan jaringan yang tidak memiliki lapisan tersembunyi. Parameter-parameter dalam pembentukan jaringan backpropagation menggunakan 3 variabel masukan, 1 atau lebih lapisan tersembunyi dan 1 lapisan keluaran. Adapun model arsitektur yang digunakan untuk mendapatkan arsitektur terbaik adalah 12-8-1, 12-16-1, 12-32-1 dan 12-64- 
1. Sebagai contoh Model sampel arsitektur 3-4-1 dapat dilihat pada gambar dibawah ini:

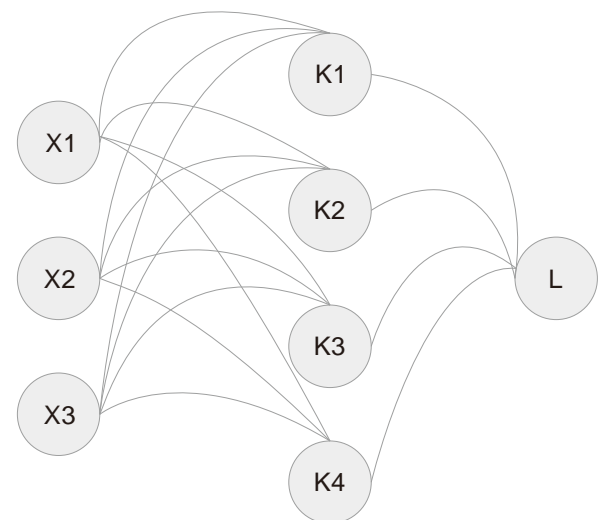

Gambar 1. Arsitektur Jaringan Saraf Tiruan dalam memprediksi Ekspor Batu Bara Menurut Negara Tujuan Utama

Jaringan Saraf yang akan dibangun adalah algoritma propagasi balik (backpropagation) dengan fungsi aktivasi Sigmoid. Fungsi aktivasi dalam Jaringan Saraf Tiruan dipakai untuk proses perhitungan terhadap nilai aktual output pada hidden layer dan menghitung nilai aktual output pada output layer.

\subsection{Pendefinisian Output}

Hasil yang diharapkan pada tahap ini adalah deteksi pola menentukan nilai terbaik untuk memprediksi Ekspor Batu Bara Menurut Negara Tujuan Utama Hasil pengujian adalah sebagai berikut :

a. Untuk mengetahui prediksi Ekspor Batu Bara Menurut Negara Tujuan Utama tentu saja didasarkan pada Data Ekspor Batu Bara Menurut Negara Tujuan Utama. Output dari prediksi ini adalah pola arsitektur terbaik dalam memprediksi Ekspor Batu Bara Menurut Negara Tujuan Utama dengan melihat error minimum.

b. Kategorisasi Output pelatihan (train) dan pengujian (test)

Kategori untuk output ditentukan oleh tingkat error minimum dari target. Batasan kategori tersebut terdapat pada tabel berikut:

Tabel 4. Data Kategorisasi

\begin{tabular}{|c|l|c|}
\hline No & \multicolumn{1}{|c|}{ Keterangan } & Error Minimum \\
\hline 1 & Benar & $0.05-0.001$ \\
\hline 2 & Salah & $>0.05$ \\
\hline
\end{tabular}

\subsection{Perancangan arsitektur Jaringan Saraf Tiruan}

Perancangan arsitektur Jaringan Saraf Tiruan untuk data pelatihan dan pengujian, maka digunakan 3 variabel input yaitu: 
Tabel 5. Perancangan Arsitektur

$\begin{array}{cccc}\text { Xelatihan } & & \text { Pengujian } \\ \text { X1 } & \text { Data Tahun 2002 } & \text { X1 } & \text { Data Tahun 2003 } \\ \text { X2 } & \text { Data Tahun 2003 } & \text { X2 } & \text { Data Tahun 2004 } \\ \text { X3 } & \text { Data Tahun 2004 } & \text { X3 } & \text { Data Tahun 2005 } \\ \text { X4 } & \text { Data Tahun 2005 } & \text { X4 } & \text { Data Tahun 2006 } \\ \text { X5 } & \text { Data Tahun 2006 } & \text { X5 } & \text { Data Tahun 2007 } \\ \text { X6 } & \text { Data Tahun 2007 } & \text { X6 } & \text { Data Tahun 2008 } \\ \text { X7 } & \text { Data Tahun 2008 } & \text { X7 } & \text { Data Tahun 2009 } \\ \text { X8 } & \text { Data Tahun 2009 } & \text { X8 } & \text { Data Tahun 2010 } \\ \text { X9 } & \text { Data Tahun 2010 } & \text { X9 } & \text { Data Tahun 2011 } \\ \text { X10 } & \text { Data Tahun 2011 } & \text { X10 } & \text { Data Tahun 2012 } \\ \text { X11 } & \text { Data Tahun 2012 } & \text { X11 } & \text { Data Tahun 2013 } \\ \text { X12 } & \text { Data Tahun 2013 } & \text { X12 } & \text { Data Tahun 2014 }\end{array}$

Berikut tahapan-tahapan yang akan dilakukan dalam pengguna algoritma propagasi balik dengan fungsi aktivasi sigmoid. Tahapan yang harus dilakukan adalah sebagi berikut:

a. Inisialisasi (initialization), merupakan tahap di mana variabel-variabel nilai akan diset atau didefinisikan terlebih dahulu, misalnya seperti: nilai data input, weight, nilai output yang diharapkan, learning rate dan nilai-nilai data lainnya.

b. Aktivasi (activation),merupakan proses perhitungan terhadap nilai aktual output pada hidden layer dan menghitung nilai actual output pada output layer.

c. Weight Training, merupakan proses perhitungan nilai error gradient pada output layer dan menghitung nilai error gradient pada hidden layer

d. Iteration, merupakan tahap akhir dalam penggujian, dimana jika masih terjadi error minimum yang diharapkan belum ditemukan maka kembali pada tahap aktivasi (activation).

3.5.1. Pelatihan dan Pengujian Arsitektur 12-16-1

Tabel 6. Perancangan Arsitektur

\begin{tabular}{lccccccccc}
\hline \multicolumn{1}{c}{ Pelatihan } & & & \multicolumn{5}{c}{ Pengujian } \\
No & Target & Output & Eror & SSE & No & Target & Output & Eror & SSE \\
\hline 1 & 0.3078 & 0.4223 & -0.1145 & 0.0131 & 1 & 0.2898 & 0.3105 & - & 0.0004 \\
& & & & & & & & 0.0207 & \\
2 & 0.1727 & 0.1680 & 0.0047 & 0.0000 & 2 & 0.1565 & 0.1558 & 0.0007 & 0.0000 \\
3 & 0.3081 & 0.5064 & -0.1983 & 0.0393 & 3 & 0.2986 & 0.4258 & - & 0.0162 \\
4 & 0.2590 & 0.3190 & -0.0600 & 0.0036 & 4 & 0.2421 & 0.2129 & 0.0292 & 0.0009 \\
5 & 0.6821 & 0.5018 & 0.1803 & 0.0325 & 5 & 0.5262 & 0.4239 & 0.1023 & 0.0105 \\
6 & 0.1942 & 0.1769 & 0.0173 & 0.0003 & 6 & 0.2037 & 0.1715 & 0.0322 & 0.0010 \\
7 & 0.1870 & 0.1400 & 0.0470 & 0.0022 & 7 & 0.1917 & 0.1202 & 0.0715 & 0.0051
\end{tabular}


Kumpulan jurnaL Ilmu Komputer (KLIK)

Volume 06, No.02 Juni 2019

ISSN: 2406-7857

\begin{tabular}{|c|c|c|c|c|c|c|c|c|c|}
\hline 8 & 0.1839 & 0.1644 & 0.0195 & 0.0004 & 8 & 0.1961 & 0.1442 & 0.0519 & 0.0027 \\
\hline 9 & 0.9000 & 0.7330 & 0.1670 & 0.0279 & 9 & 0.8302 & 0.7694 & 0.0608 & 0.0037 \\
\hline 10 & 0.1064 & 0.1480 & -0.0416 & 0.0017 & 10 & 0.1030 & 0.1264 & $\begin{array}{l}- \\
0.0234\end{array}$ & 0.0005 \\
\hline 11 & 0.1194 & 0.1395 & -0.0201 & 0.0004 & 11 & 0.1170 & 0.1081 & 0.0089 & 0.0001 \\
\hline 12 & 0.1227 & 0.1255 & -0.0028 & 0.0000 & 12 & 0.1271 & 0.1336 & $-\overline{0.0065}$ & 0.0000 \\
\hline 13 & 0.1392 & 0.2315 & -0.0923 & 0.0085 & 13 & 0.1575 & 0.1804 & $\begin{array}{l}- \\
0.0229\end{array}$ & 0.0005 \\
\hline \multicolumn{3}{|c|}{ Total } & \multicolumn{2}{|c|}{0.1300} & \multicolumn{3}{|c|}{ Total } & \multicolumn{2}{|c|}{0.0417} \\
\hline \multicolumn{2}{|c|}{ MSE } & & \multicolumn{2}{|c|}{0.0100} & \multicolumn{3}{|c|}{ MSE } & \multicolumn{2}{|c|}{0.0032} \\
\hline & & & & & \multicolumn{3}{|c|}{ Akurasi } & \multicolumn{2}{|c|}{$100 \%$} \\
\hline
\end{tabular}

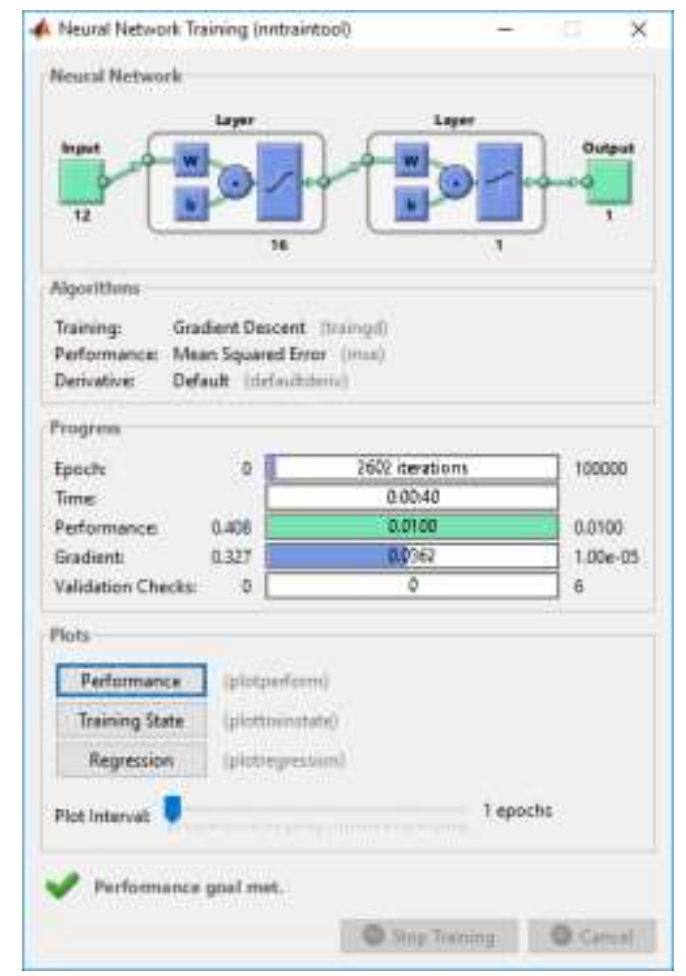

Gambar 4. Pelatihan Model 12-16-1 


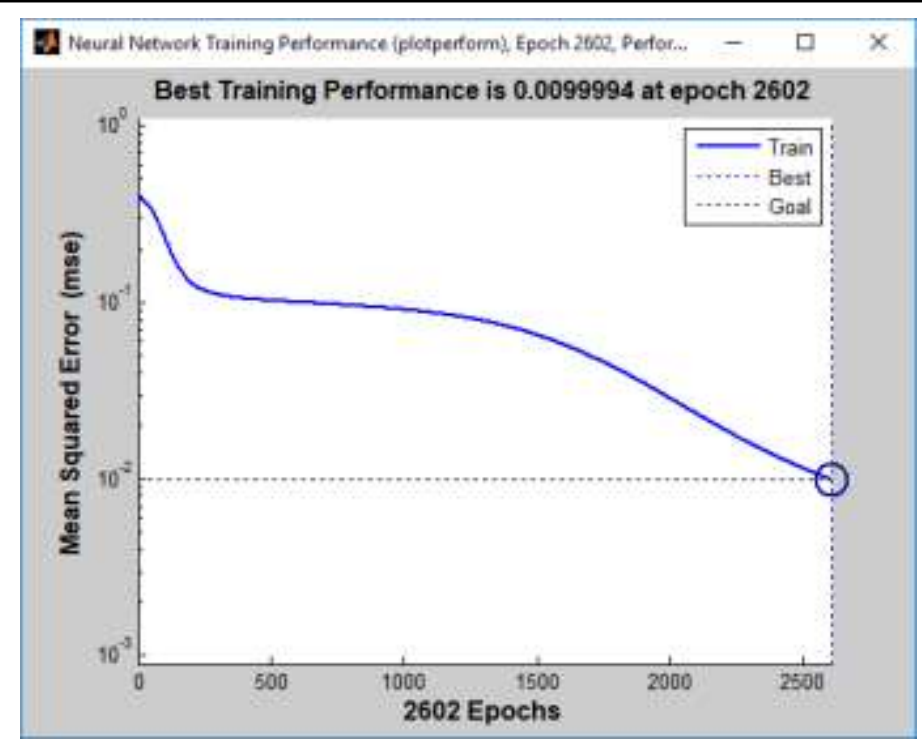

Gambar 5. Performance Model 12-16-1

\subsubsection{Pemilihan Arsitektur Terbaik Jaringan Saraf Tiruan}

Setelah selesai melakukan pelatihan dan pengujian terhadap model 12-8-1, 12-16-1, 12-32-1 dan 12-64-1 menggunakan data-data yang ada, maka di hasilkan output berupa akurasi kebenaran, jumlah epochs dan MSE dari setiap model. Arsitektur yang terbaik dapat dilihat dari tingkat akurasi kebenaran, sedikit banyaknya epochs dan besar kecil nya MSE. Berikut adalah data akurasi, jumlah epochs dan MSE dari model yang telah diuji.

Tabel 6. Hasil Rekapitulasi Model

\begin{tabular}{lcccc}
\hline \multicolumn{5}{c}{ Rekapitulasi Model } \\
\hline Model & $12-8-1$ & $12-16-1$ & $12-32-1$ & $12-64-1$ \\
Epochs & 4751 & 2602 & 1938 & 397 \\
MSE & 0.0080 & 0.0032 & 0.0278 & 0.0261 \\
Akurasi & $100 \%$ & $100 \%$ & $85 \%$ & $85 \%$ \\
\hline
\end{tabular}

Berdasarkan hasil diatas maka didapat model arsitektur terbaik diantara model 12-8-1, 12-16-1, 12-32-1 dan 12-64-1 adalah model 12-16-1 dengan akurasi kebenaran 100\%, jumlah epochs 2602 dan MSE sebesar 0.0032. Berikut ini adalah hasil pelatihan dan pengujian data menggunakan arsitektur 12-16-1.

\section{SIMPULAN}

Berdasarkan penelitian diatas dapat ditarik kesimpulan antara lain :

a. Model Arsitektur Jaringan Syaraf Tiruan dapat digunakan untuk memprediksi jumlah ekspor batu bara menurut negara tujuan utama dalam mendorong laju pertumbuhan ekonomi.

b. Banyaknya hidden layer tidak menjamin kualitas pengujian semakin baik. 
c. Dari lima arsitektur yang di uji yaitu 12-8-1, 12-16-1, 12-32-1 dan 12-64-1, didapatkan arsitektur 12-16-1 adalah arsitektur terbaik dengan akurasi 100\% dan MSE 0.0032.

\section{DAFTAR PUSTAKA}

[1] Solikhun and M. Safii, “Jaringan Saraf Tiruan Untuk Memprediksi Tingkat Pemahaman Siswa Terhadap Mata Pelajaran Dengan Menggunakan Algoritma Backpropagation," J. Sains Komput. Inform., vol. 1, no. 1, pp. 24-36, 2017.

[2] A. Sudarsono, "JARINGAN SYARAF TIRUAN UNTUK MEMPREDIKSI LAJU PERTUMBUHAN PENDUDUK MENGGUNAKAN METODE BACPROPAGATION (STUDI KASUS DI KOTA BENGKULU)," Media Infotama, vol. 12, no. 1, pp. 6169, 2016.

[3] A. Revi, Solikhun, and I. Parlina, "Jaringan Syaraf Tiruan Dalam Memprediksi Tingkat Pertumbuhan Industri Mikro Dan Kecil Berdasarkan Provinsi," TEKNIKA, vol. 7, no. November, 2018.

[4] A. P. Windarto, "IMPLEMENTASI JST DALAM MENENTUKAN KELAYAKAN NASABAH PINJAMAN KUR PADA BANK MANDIRI MIKRO SERBELAWAN DENGAN METODE BACKPROPOGATION Agus," Sains Komput. Inform., vol. 1, no. 1, pp. 12-23, 2017.

[5] A. Jumarwanto, R. Hartanto, and D. Prastiyanto, "APLIKASI JARINGAN SARAF TIRUAN BACKPROPAGATION UNTUK MEMPREDIKSI PENYAKIT THT DI RUMAH SAKIT MARDI RAHAYU KUDUS," J. Tek. Elektro, vol. 1, no. 1, pp. 1121, 2009.

[6] D. O. Maru'ao, "Neural Network Implementation in Foreign Exchange Kurs Prediction," 2010.

[7] A. P. Windarto, P. Studi, and S. Informasi, "Implementasi JST Dalam Menentukan Kelayakan Nasabah Pinjaman KUR Pada Bank Mandiri Mikro Serbelawan Dengan Metode Backpropagation," no. 1, pp. 12-23, 2017. 